\title{
Subcapsular haematoma of the spleen complicating acute pancreatitis
}

\author{
Ardy Fenando, ${ }^{1}$ Shilpa Tatineni, ${ }^{1}$ Fazal I Raziq, ${ }^{1}$ Ahmad Alratroot ${ }^{1,2}$
}

'Department of Internal Medicine, Michigan States University, Lansing, Michigan, USA

${ }^{2}$ Internal Medicine, Sparrow Hospital, Lansing, Michigan, USA

\section{Correspondence to} Dr Ardy Fenando, Fenandoa@msu.edu

Accepted 27 August 2019

\section{DESCRIPTION}

A 63-year-old man with a medical history significant for alcohol abuse and ischaemic cardiomyopathy presented to our hospital with a complaint of abdominal pain. The pain was mainly located in the left upper quadrant, non-radiating, intermittent, and the severity was initially around $7 / 10$ but worsening in the morning prior to admission. He denied any history of fall or recent trauma. He was recently admitted to a local hospital and diagnosed with acute pancreatitis. He denied any other previous episode of pancreatitis or history of biliary stones. He admitted to drinking alcohol every night, with alcohol consumption of 60-80 g/ day. In the hospital, his vital signs were only significant for a blood pressure of $160 / 110 \mathrm{~mm} \mathrm{Hg}$. His abdominal examination revealed some tenderness in the left upper quadrant with a palpable spleen under the left costa. The pertinent laboratory findings were decreased haemoglobin $(11.5 \mathrm{~g} / \mathrm{dL})$, mildly elevated aspartate transaminase $(61 \mathrm{U} / \mathrm{L})$ and elevated lipase $(151 \mathrm{U} / \mathrm{L})$. The abdominal CT scan revealed a subcapsular haematoma of the spleen extending over $86 \mathrm{~mm}$ oblique anterior-posterior by $31 \mathrm{~mm}$ oblique transverse, there was adjacent fluid extending from the region of the tail of pancreas reveals both interstitial and peripancreatic oedema, and there was blood adjacent to the spleen and extending along the left paracolic gutter lateral to the descending colon (figure 1). During the stay, conservative managements with fluid, pain control and symptomatic treatment were initiated. Echocardiogram was done due to the concern of mild difficulty in breathing which showed small left ventricular thrombus. Heparin was started after we considered the risk of having emboli greater than

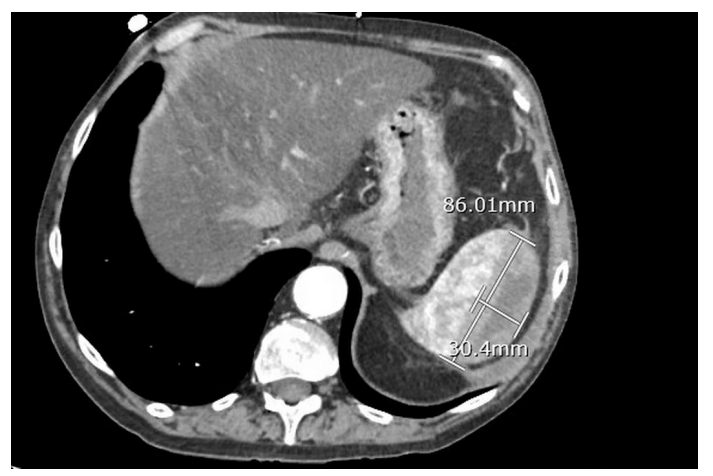

Figure 1 CT abdomen axial slice. Subcapsular haematoma of the spleen with adjacent fluid around the tail of pancreas and blood adjacent to the spleen and extending along the left paracolic gutter.

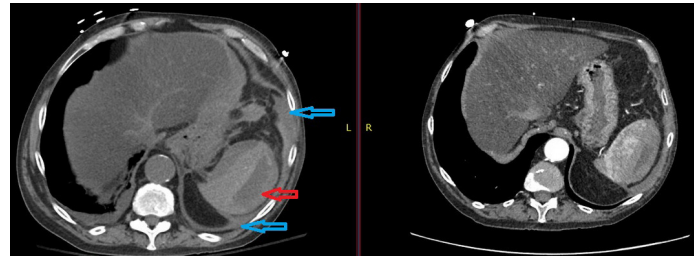

Figure 2 CT abdomen axial slice. The picture on the left side showing an increase in the size of the haematoma (red arrow) and expansion of the haemorrhagic fluid around the spleen (blue arrow).

bleeding. On the second day of receiving heparin, he suddenly developed worsened abdominal pain in the left upper quadrant, tachycardia and hypotension. The haemoglobin dropped for about $2 \mathrm{~g} /$ $\mathrm{dL}$ from his baseline. Heparin was immediately stopped. The abdominal CT scan was repeated and showed an interim increase in haemorrhagic fluid involving the abdomen and pelvis with maximal hyperdensity in the region of the spleen and increase in size of subcapsular splenic haematoma (figures 2 and 3). A total of 6 units of packed red blood cell transfused to stabilise the patient. The patient was transferred to the intensive care unit and surgery team immediately consulted. Splenectomy was later performed. Intraoperative findings included a large amount of haemoperitoneum consistent with old blood and clot with a grade 4 splenic rupture.

Splenic subcapsular haematoma is a very rare complication of acute or chronic pancreatitis. One study estimated its prevalence to be $0.4 \%$ in 500 patients with chronic pancreatitis. ${ }^{1}$ Subcapsular haematoma is probably the rarest complication of pancreatitis. To our knowledge, there were only several subcapsular haematoma cases reported which most of them had pseudocyst in the tail of pancreas identified as the culprit of the haematoma. ${ }^{1-3}$ In our case, a fall causing splenic trauma

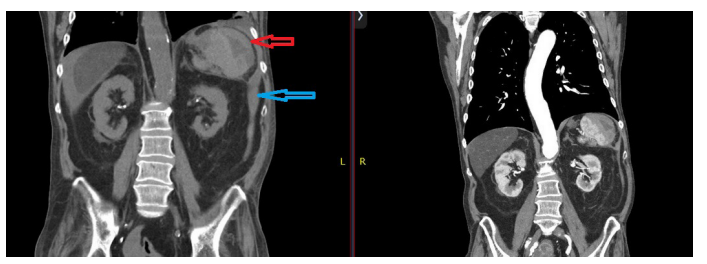

Figure $3 \mathrm{CT}$ abdomen coronal view. The picture on the left side showing an increase in the size of the haematoma (red arrow) and expansion of the haemorrhagic fluid involving the abdomen and pelvis with maximal hyperdensity in the region of the spleen (blue arrow). 
would be at least as likely as he had no history of fall or trauma. The pancreatitis is the most likely the aetiology of the haematoma. Another interesting fact about the case is that this was only the first recurrent episode of acute pancreatitis without any formation of a pseudocyst.

Several theories that might explain this occurrence include: (1) pancreatic enzymes' leakage which causing some damage to the splenic parenchyma; (2) disruption of splenic hilar vessels that could potentially lead to subcapsular haematoma; (3) expansion of intrasplenic pseudocysts resulting in spleen rupture and bleeding. ${ }^{2}$ Diagnosis of subcapsular haematoma of the spleen is challenging and requires a high index of suspicious. From the history taking, patients with symptoms of pancreatitis accompanied by left upper quadrant pain that radiating to the left

Learning points

Splenic subcapsular haematoma is one of the rarest complications of acute or chronic pancreatitis but it can cause life-threatening bleeding when it ruptures.

- Diagnosis of acute pancreatitis does not require any imaging but we need to have a high index of suspicious in patients who exhibit above signs and symptoms. CT scan and MRI should be done early in those patients.

- Management of subcapsular haematoma remains controversial although some experts recommend doing some pressure reduction such as percutaneous drainage or laparotomy or even early splenectomy. shoulder. On the physical examination, we usually appreciate some tenderness with a mass in the left upper quadrant. Laboratory finding can include a drop in haematocrit. Imaging studies such as CT scan and MRI should be performed early in patients who exhibit those findings. ${ }^{2}$ The management of subcapsular haematoma remains controversial due to the rarity of the case. ${ }^{14}$ Some suggested to do some pressure reduction by percutaneous drainage or laparotomy for large splenic haematoma $(>5 \mathrm{~cm})$. Some reports even recommended more aggressive treatment with early splenectomy. ${ }^{4}$

Contributors AF, ST and FIR: wrote the primary manuscript. AA: revised the manuscript.

Funding The authors have not declared a specific grant for this research from any funding agency in the public, commercial or not-for-profit sectors.

Competing interests None declared.

Patient consent for publication Obtained.

Provenance and peer review Not commissioned; externally peer reviewed.

\section{REFERENCES}

1 Patel VG, Eltayeb OM, Zakaria M, et al. Spontaneous subcapsular splenic hematoma: a rare complication of pancreatitis. Am Surg 2005;71:1066-9.

2 Zhang S, Liu F, Buch H, et al. Large subcapsular splenic hematoma with a large pancreatic pseudocyst was successfully treated with splenic arterial embolization and ultrasound-guided percutaneous drainage of pancreatic pseudocyst. Case Rep Med 2017;2017:1-5.

3 Fatima S, Losanoff JE, Khouri N, et al. Giant subcapsular hematoma of the spleen complicating recurrent pancreatitis. Am Surg 2012;78:E120.

4 Tseng CW, Chen CC, Chiang JH, et al. Percutaneous drainage of large subcapsular hematoma of the spleen complicating acute pancreatitis. J Chin Med Assoc 2008;71:92-5.

Copyright 2019 BMJ Publishing Group. All rights reserved. For permission to reuse any of this content visit

https://www.bmj.com/company/products-services/rights-and-licensing/permissions/

BMJ Case Report Fellows may re-use this article for personal use and teaching without any further permission.

Become a Fellow of BMJ Case Reports today and you can:

- Submit as many cases as you like

- Enjoy fast sympathetic peer review and rapid publication of accepted articles

- Access all the published articles

Re-use any of the published material for personal use and teaching without further permission

Customer Service

If you have any further queries about your subscription, please contact our customer services team on +44 (0) 2071111105 or via email at support@bmj.com.

Visit casereports.bmj.com for more articles like this and to become a Fellow 